\title{
Primeros levantamientos cartográficos generales de Chile con base científica: los mapas de Claudio Gay y Amado Pissis ${ }^{1}$
}

\author{
José Ignacio González Leiva²
}

\begin{abstract}
RESUMEN
Las autoridades de gobierno, desde principios de la vida republicana de la nación chilena, trataron de resolver la carencia de una cartografía general del país con un cierto nivel de exactitud. Esto les permitiría conocer su forma, extensión, localización de la población, así como también la ubicación de los recursos naturales. En este contexto, se explica la contratación en 1830 del naturalista francés Claudio Gay y posteriormente, en 1848, del geólogo y geógrafo francés Amado Pissis, con el fin de suplir dicha falta mediante levantamientos cartográficos, que se encomendaron a ambos del territorio nacional.

Los trabajos realizados tanto por Gay como por Pissis, son analizados desde el punto de vista cartográfico, en primer lugar con el fin de conocer los procedimientos seguidos en su elaboración como asimismo los resultados, y en segundo lugar, con el objetivo de constatar el cumplimiento de los requerimientos solicitados por las autoridades de gobierno, a la luz de los contratos firmados por ambos.
\end{abstract}

Palabras clave: Cartografía chilena, historia de la cartografía, Claudio Gay, Amado Pissis.

\begin{abstract}
The government authorities, from the beginning of the republican life of the Chilean nation, tried to resolve the lack of general cartography of the country with a certain level of accuracy. This would allow them to get to know its form, extension, location of the population; as well as the location of its natural resources. This context also explains the hiring in 1830 of the French naturalist Claudio Gay and later, in 1848, of the French geologist and geographer Amado Pissis, in order to substitute such problems so for both to make a cartographic survey of the national territory. The work done by Gay and Pissis, are here analyzed from the cartographic point of view; first of all to know the procedures followed by the elaborations as well as the results obtained, and secondly to comply with the requirements asked by the government authorities, based on the contracts signed by both of them.
\end{abstract}

Key words: Chilean cartography, history of the cartography, Claudio Gay, Amado Pissis.

\footnotetext{
1 Proyecto Fondecyt № 1051016. “Ciencia y nacionalidad, la obra científica de Claudio Gay en la formación de la nación chilena". Artículo recibido el 13 de abril de 2007 y aceptado el 9 de septiembre de 2007.
}

2 Instituto de Geografía, Pontificia Universidad Católica de Chile, Santiago de Chile (Chile). E-Mail: jigonzal@uc.cl 
La cartografía realizada en el territorio perteneciente a la gobernación de Chile durante la Colonia, fundada en sistemas de levantamientos científicos de cierta precisión bajo la administración hispana, se reducía básicamente a lo efectuado por la expedición de Antonio de Córdova y Lasso de la Vega, en el área del estrecho de Magallanes (1785-1789); lo levantado por José de Moraleda en el sector de Chiloé, Valdivia y los canales (1793-1795) y lo ejecutado por la expedición de Alejandro de Malaspina, a su paso por el litoral chileno (1789-1794). Sin embargo, los dos primeros se reducían solo a sectores muy específicos del territorio y el último, esencialmente a la línea de costa, sin contar además, que no estaban a disposición de las autoridades chilenas durante los primeros años de vida independiente.

En virtud de lo anterior, desde los inicios de la vida republicana, las autoridades de gobierno evidenciaron la necesidad de que el país contara con una cobertura cartográfica que comprendiera en lo posible todo el territorio nacional, cartografía tanto del tipo hidrográfica como topográfica. Ella permitiría conocer la forma del territorio, así como también las dimensiones del espacio geográfico heredado de la corona hispana. Además, el hecho de poder contar con tales coberturas, se consideraba fundamental para fines militares, de administración y ordenación del territorio.

En relación con la cartografía hidrográfica, el piloto Claudio Vila, en 1823, interesó al Ministro del Interior, don Mariano Egaña, para llevar adelante la creación de una Academia Náutica. Entre otros propósitos, debería formar pilotos para la navegación y suplir la carencia de un levantamiento hidrográfico de las costas de Chile. En su presentación argumentaba que: "dicho trabajo facilitaría posteriormente el levantamiento de la carta geográfica del interior del territorio" (Greve, 1950: 11). Emprender una tarea de esta naturaleza permitiría al país no depender de manera tan directa de potencias europeas como Gran Bretaña y España, toda vez que ellas habían mostrado especial interés por la realización de levantamientos hidrográficos en la América meridional. Para el caso de Chile, son conocidos los trabajos realizados por el Depósito Hidrográfico de Madrid a principios del siglo XIX, organismo que publicó cartas hidrográficas de las costas y puertos de nuestro país, levantadas por la expedición de Alejandro Malaspina, así como también las cartas del hidrógrafo inglés Norie de los años 1822 y 1824 y las del Almirantazgo Británico de la década de 1830. Para contrarrestar en parte lo anterior, en 1835 el Ministerio de Marina de Chile, publicó una carta de gran parte del litoral chileno titulada "Carta incompleta de la Costa de Chile", basada en el trabajo realizado por el hidrógrafo inglés Robert Fitz Roy. Años más tarde, los esfuerzos por disponer de una cartografía hidrográfica propia llevan a crear en el año 1874 la Oficina Hidrográfica, dependiente del Ministerio de Marina, la cual debía, entre otros objetivos, publicar cartas hidrográficas y el Anuario Hidrográfico de la Marina de Chile. Fundador y primer director de dicha Oficina fue el destacado marino Francisco vidal Gormaz.

Por otra parte, en lo referente a cartografía terrestre o topográfica de la gobernación de Chile, su carencia era prácticamente total. Lo realizado por las autoridades españolas para este territorio no estaba fundado en la rigurosidad científica que otorgan los métodos con base astronómica, por lo que solo tenían el carácter de esquicios cartográficos. Entre otros, se pueden mencionar las cartas de Juan López de Velasco, Antonio de Herrera, Ambrosio O'Higgins y Andrés Baleato. Hace excepción de lo anterior, la carta topográfica que levanta la expedición de Malaspina para mostrar el camino que une Santiago de Chile con Buenos Aires a través del paso de la cordillera de los Andes; carta, que aunque muy reducida en latitud, era de gran calidad y solo vino a ser publicada por el Depósito Hidrográfico de Madrid en 1810 , la que en opinión de José Toribio Medina, "puede estimarse como el primer trabajo geodésico hecho de una sección del territorio de Chile" (Medina, 1889). No es de extrañar entonces que las autoridades republicanas comisionen por Decreto Supremo del 20 de diciembre de 1823, al geógrafo don Carlos Francisco Ambrosio Lozier y al coronel de Ingenieros don José Alberto Backler D'Albe, para ejecutar el mapa geográfico de Chile. No obstante lo anterior, y como 
consecuencia de los escasos medios que se pusieron a su alcance y al deceso de su compañero Backler D'Albe, Lozier no pudo cumplir con la realización de la carta topográfica solicitada, por lo que su "obra quedó reducida a algunos trabajos en la desembocadura del Bío Bío" (Errázuriz, 1981: 12).

En este contexto y ante la necesidad de disponer de una cobertura cartografía con base científica que cubriera todo el país, el gobierno de Chile a través de su Ministro del Interior Diego Portales, contrató primero, con fecha 14 de septiembre de 1830 al naturalista francés Claudio Gay. Este debería ocuparse, entre otras cosas, de la realización de un viaje de reconocimiento de la naturaleza por todo el territorio de la república, así como también de la ejecución de cartas, planos y láminas de las principales ciudades, puertos y ríos. Estos encargos se materializarían mediante una relación geográfica y un levantamiento cartográfico de la república. Posteriormente, según el documento firmado el 10 de octubre de 1848, el Ministro del Interior Camilo Vial, contrató los servicios del geógrafo y geólogo francés Amado Pissis, para realizar una tarea similar a la de Gay, como era levantar el Plano Topográfico y Geológico de Chile, la que en esencia debía traducirse en una obra compuesta de un texto y un conjunto de mapas del territorio chileno.

Para el cumplimiento de estos y otros propósitos contemplados en el contrato, Claudio Gay recorrió el país entre 1830 y 1842, cubriendo el espacio comprendido entre el despoblado de Atacama y la isla Grande de Chiloé. En París, en 1854, y con el nombre de "Atlas de la Historia Física y Política de Chile", se inició la publicación de la obra que solo culminaría en 1864. Formando parte del Atlas se encuentra: un mapa general de Chile, doce mapas provinciales y varios planos de ciudades y puertos.

Por su parte, la tarea que el gobierno encargó a Amado Pissis, se centraba en dos asuntos bien específicos: por el primero se solicitaba elaborar una cobertura cartográfica del país de la mayor precisión posible y por el segundo, levantar un catastro del potencial geológico del territorio nacional. Para llevar a cabo la solicitud demandada, recorrió el país entre 1848 y 1865 , período en el que cubre gran parte del territorio chileno, desde el desierto de Atacama hasta las proximidades de la Araucanía. Como respuesta a lo solicitado, publica en París, en 1873, el "Plano Topográfico y Geológico de la República de Chile" a escala 1: 250.000. Luego, como complemento de lo anterior, publica en 1888, el "Mapa de la República de Chile desde el río Loa hasta el cabo de Hornos" a escala 1: 1.000.000.

Hay que hacer presente que en la época en que Claudio Gay inicia su viaje de exploración en nuestro país, otros naturalistas realizan trabajos similares en América como Alcides d'Orbigny, en la cuenca del río de la Plata; Carlos Darwin en las costas orientales y occidentales de las actuales repúblicas de Argentina y Chile, y Alexander von Humboldt completaba la publicación de sus trabajos en la América equinoccial (Gangas, 1985a: 175). De lo que se desprende que el trabajo que se efectúa en Chile no es un hecho particular ni único dentro del contexto americano. Por otra parte, coetáneo al trabajo que lleva a cabo Amado Pissis, colaboran al reconocimiento del país, desde sus particulares puntos de vista Ignacio Domeyko y Rodolfo Amando Philippi.

Los objetivos que guían el presente trabajo, se orientan a conocer la contribución del naturalista Claudio Gay y del geógrafo y geólogo Amado Pissis, al conocimiento geográfico del territorio nacional, a través de las obras cartográficas que ellos realizan por encargo de los gobiernos de la República. Al mismo tiempo, se pretende determinar el alcance y valor científico de la cartografía elaborada por ellos, en relación con los métodos de levantamiento y representación cartográfica imperantes en su época.

La metodología seguida en el cumplimiento de los objetivos propuestos, se orientó a conocer el contexto en que se realizan los encargos gubernamentales de elaborar coberturas cartográficas de territorio nacional, en primer término a Claudio Gay en 1830 y posteriormente, a Amado Pissis en 1848. Para ello, se analizan los textos de los contratos firmados entre las autoridades de gobierno tanto con Gay como con Pissis, la correspondencia vinculada con la elabora- 
ción de la cartografía, así como también las opiniones que se vertieron sobre el producto cartográfico generado por ellos.

Enseguida, teniendo como base las cartas y mapas elaborados por Gay y Pissis, se procedió a conocer los métodos empleados en los levantamientos, instrumentos utilizados para su ejecución, proyecciones cartográficas escogidas, escalas ocupadas en las representaciones tanto general del país como de cada una de las provincias, toponimia, representación del relieve, etc. Todo lo anterior, con la finalidad de determinar la calidad y el valor científico de los levantamientos cartográficos realizados.

\section{El contexto de la cartografía}

En el instante que se llevan a cabo los levantamientos cartográficos solicitados a Claudio Gay y Amado Pissis, la cartografía como disciplina científica había dado un salto importante en su desarrollo, especialmente en lo relacionado a calidad y cantidad de su producción, en atención a que entre mediados del siglo XVII y finales del siglo XVIII mejoran sustancialmente los instrumentos, alcanzando un alto grado de precisión y exactitud las mediciones y donde también, se introducen métodos más eficientes para el trabajo en terreno de topógrafos y geomensores. En efecto, esta época se reconoce como aquella donde las ciencias en general y la cartografía en particular experimentan profundos cambios y transformaciones.

Entre los instrumentos que se perfeccionan o se crean, destacan entre otros, el teodolito, utilizado en la medición de ángulos horizontales y verticales; el sextante y el octante, empleados en la determinación de la latitud y el cronómetro, fundamental en el cálculo de la longitud. Por otra parte, los métodos empleados en los levantamientos cartográficos, con los progresos señalados anteriormente, también se verán afectados. La Academia de Ciencias de Francia, creada en 1666, adopta el método propuesto por Gemma Frisius en el siglo XVI para los levantamientos cartográficos conocido como triangulación. En esencia, el método de Frisius requería para su aplicación establecer una línea de base, es decir, medir con gran precisión una determinada magnitud en el terreno, expresada en una unidad de medida y materializada en una línea que sirve de punto de partida para la ejecución de la triangulación geodésica. Es necesario además, posesionar astronómicamente los puntos extremos de dicha línea, es decir, calcular su valor en latitud y longitud. Teniendo determinada la magnitud de la línea y la localización de los puntos extremos, se lleva a cabo la triangulación: ella consiste en situar astronómicamente otros puntos del terreno y formar con ellos una serie de triángulos en el área que se desea aplicar. Establecida la magnitud de la línea de base, es necesario medir los ángulos que se generan desde los extremos de la línea, hacia un tercer punto u objeto que se ubica en el terreno, para así determinar un triángulo lo más equilátero posible. De esta manera, con la ayuda de cálculos geométricos se conoce la distancia que hay al punto u objeto que está en el vértice del triángulo y por interpolación determinarle sus coordenadas geográficas, para luego calcular la superficie que cubre el triángulo en el terreno. En el momento que se puso en uso la triangulación, como método para los levantamientos cartográficos, este fue utilizado cada vez con mayor frecuencia en reemplazo de otros métodos menos precisos como el de plancheta, lo que junto con los otros progresos señalados anteriormente, dará paso a una cartografía cada vez más científica.

El primer país que confecciona una carta topográfica basada en una triangulación geodésica será Francia. Para ejecutar lo anterior fue necesario realizar una triangulación completa del país, hecho que permitió que en 1720 Jacques Cassini pudiera publicar una nueva carta de Francia, en la que se hacía presente que esta había sido corregida por orden del Rey teniendo en cuenta las observaciones de los señores de la Academia de Ciencias. En 1740, cuando la triangulación de Francia había concluido para todo el territorio francés, César Francois Cassini de Thury publica a su vez una nueva carta de Francia a escala 1: 878.000, quien aprovecha el éxito de ella para presentar al rey Luis XIV un proyecto para levantar una carta de Francia a gran escala, obra que llegó a ser conocida como Carta de Cassini. Para su realización transcurrie- 
ron más de cuarenta años, al cabo de los cuales fue presentada a la Asamblea Nacional en 1789. Esta cobertura cartográfica a escala 1: 86.400 está compuesta por 148 hojas.

En relación con la carta de Cassini, George Kish dice que: "será el prototipo de todos los grandes proyectos cartográficos de los siglos XIX y XX, conteniendo todos los detalles geodésicos esenciales. Todo lo que progresa posteriormente, se relaciona con la precisión de los instrumentos y con los procedimientos de impresión más eficaces. Pero la carta de Cassini constituye una de las grandes realizaciones cartográficas de todos los tiempos: elegancia en su ejecución, claridad de su dibujo, con una presentación que constituye un estándar raramente sobrepasada en el curso de los dos siglos siguientes de su publicación" (Kish, 1980: 57).

\section{Primer mapa de una parte del territorio chileno con base científica}

La expedición científica comandada por Alejandro Malaspina y secundado por el capitán José Bustamante y Guerra, efectuada entre 1789 y 1794 por los territorios hispanos de ultramar, tenía entre otros propósitos el realizar levantamiento cartográfico de los sectores que se visitaran durante el viaje. Dicha cartografía, por la naturaleza de la expedición, debía ser preferentemente hidrográfica o náutica, lo que se materializó esencialmente en cartas del litoral y puertos, además de perfiles de las costas. Su finalidad era en definitiva, el poder disponer de una cartografía de gran exactitud que brindara la necesaria seguridad a la navegación por estos territorios. No obstante, en forma ocasional, la expedición efectuó cartografía terrestre, cuando miembros de la expedición se internaron hacia el interior de los territorios visitados, hecho que les permitió reconocer las características topográficas de dichos espacios (Sagredo, 2004: 124).

En su paso por Chile, la misión cartográfica se cumplió cabalmente, lo que dejó como patrimonio numerosas cartas y pla- nos de los lugares visitados, especialmente puertos, vistas de la costa y determinación de coordenadas geográficas para 26 puntos entre el cabo de Hornos y el puerto de Arica.

Para el cumplimiento del objetivo relacionado con los levantamientos cartográficos, las embarcaciones que comprendían la expedición: la "Descubierta" y la "Atrevida" contaban con una dotación de marinos y oficiales especialmente preparados para el efecto, así como también los más modernos instrumentos disponibles en la época, los cuales les eran indispensables para realizar las observaciones astronómicas y los cálculos matemáticos requeridos para la elaboración de una cartografía de calidad. En efecto, disponían de relojes de péndulo, cronómetros, cuadrantes, sextantes, agujas de inclinación, teodolitos y anteojos astronómicos.

Los levantamientos de cartografía terrestre o topográfica realizados por la expedición en el ámbito de la gobernación de Chile fueron reducidos, dado que el interés central de tales trabajos era la cartografía náutica o hidrográfica. A pesar ello, se realizaron algunos trabajos cartográficos terrestres de gran calidad, entre estos destaca uno que puede ser considerado como el primero de su tipo con carácter científico para una parte del territorio chileno. El mapa abarca una franja de $9^{\circ}$ en latitud y $16^{\circ}$ en longitud, tiene como extremos de su eje Oeste-Este, las ciudades de Valparaíso y Buenos Aires. El levantamiento de este mapa estuvo a cargo de los oficiales Felipe Bauzá y José Espinoza y Tello, realizado en 1794 y publicado en 1810 por la Dirección de Hidrografía de Madrid, con el título de "Carta esférica de la parte interior de América del Sur para manifestar el camino que conduce desde Valparaíso a Buenos Aires, construido por las observaciones que se hicieron en esos parajes en 1794", representación confeccionada a una escala aproximada de 1: 1.800.000 (Figura № 1). Forma parte también de este mapa, ubicado en un recuadro de él, otro mapa titulado "Plano del Paso de Los Andes" a una escala aproximada de 1:1.500.000 de los mismos autores, el que también se publicó de manera independiente (Figura № 2). 
Figura № 1

CARTA ESFÉRICA DEL INTERIOR DE AMÉRICA MERIDIONAL, LEVANTADA EN 1794 Y PUBLICADA EN 1810 POR LA DIRECCIÓN HIDROGRÁFICA DE MADRID. EN UN RECUADRO Y, FORMANDO PARTE DE ELLA, SE ENCUENTRA EL "PLANO DEL PASO DE LOS ANDES"

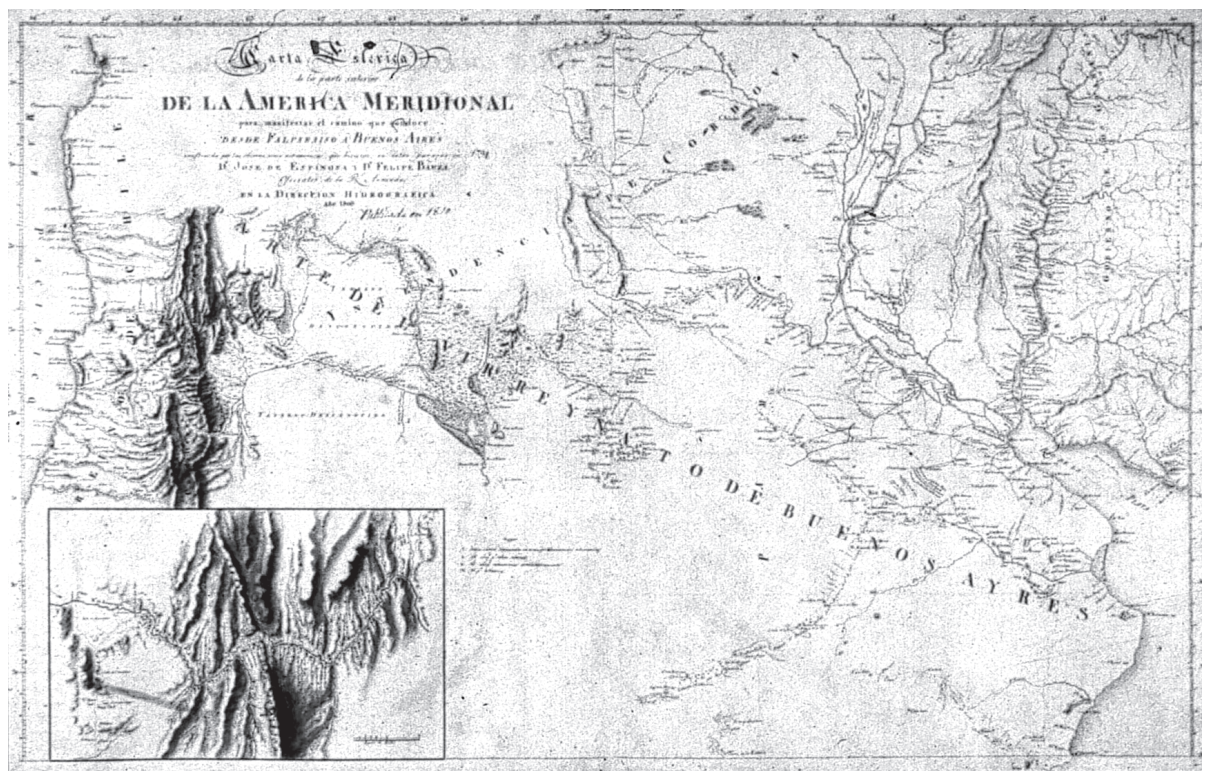

Fuente: Museo Naval de Madrid.

Figura № 2

CARTA IMPRESA DEL "PLANO DEL PASO DE LOS ANDES", LEVANTADA EN TERRENO EL AÑO 1794 Y PUBLICADA POR LA DIRECCIÓN HIDROGRÁFICA DE MADRID, EL AÑO 1811

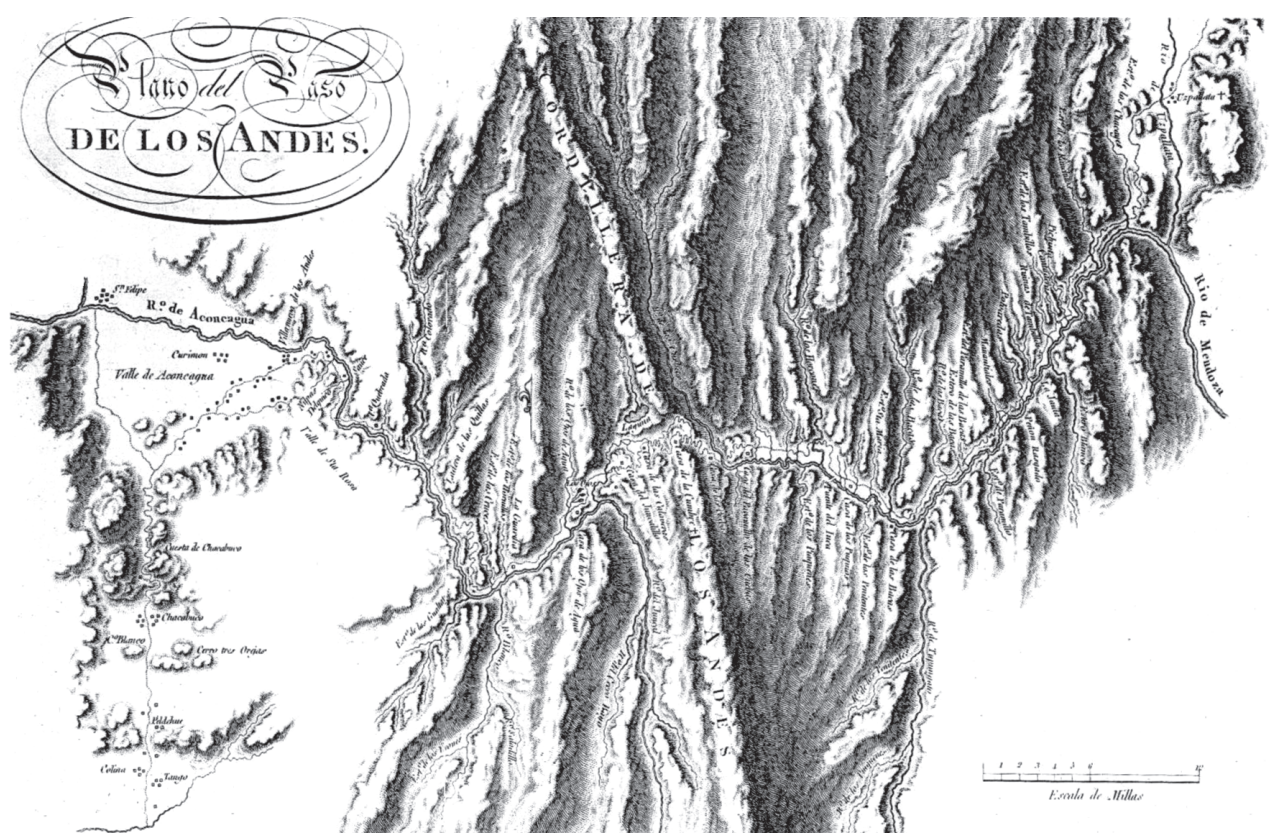

Fuente: Museo Naval de Madrid. 
El método utilizado por los miembros de la expedición de Malaspina para la ejecución de los levantamientos cartográficos es el de la triangulación. La cartografía de tipo terrestre o topográfica que ellos producen es, desde el punto de vista cartográfico, de buena calidad en cuanto a su diseño y nivel de precisión, la que puede equipararse con la que imperaba en Europa en esa época, especialmente con el modelo impuesto por la familia Cassini para el mapa topográfico de Francia. Especial mención merece también la técnica que utilizan los autores de este mapa, Felipe Bauzá y José Espinoza y Tello para representar el relieve mediante el método de las normales, iluminadas oblicuamente: técnica que proporciona la ilusión visual de una superficie en tres dimensiones (González, 2004: 26); los cursos de agua están representados por dos líneas continuas zigzagueantes; los caminos por medio de dos líneas paralelas de diferente grosor según su importancia y la localización de los centros poblados, mediante símbolos puntuales de diferente tamaño para diferenciar ciudades, pueblos, aldeas. Por lo anterior, este mapa ha sido motivo de especiales elogios para resaltar sus aciertos como representación cartográfica, tanto para la Carta esférica de América Meridional como para la del recuadro que se destina a representar el Paso de los Andes. Rodolfo Núñez de las Cuevas dice: "una de las expediciones más destacadas fue la realizada por Bauzá y Espinoza de Valparaíso a Río de la Plata, en 1794, atravesando la cordillera de los Andes. El resultado de este viaje fue la formación de una de las cartas más bellas de la expedición, titulada Camino de Valparaíso a Buenos Aires" (Núñez de las Cuevas, 1987).

María Luisa Martín Merás, al referirse a la cartografía elaborada por la expedición Malaspina dice que ella "sirvió durante muchos años a los países americanos como punto de partida para elaborar sus propias cartas, tarea que por distintas circunstancias, no han acometido hasta principios de este siglo" (Martín, 1993: 218). En el caso chileno, ella no tuvo mayor incidencia en quienes posteriormente llegarían a realizar los primeros levantamientos cartográficos sistemáticos en Chile con fundamentos científicos, ya que aunque Claudio Gay visitó el Depósito Hidrográfico de Madrid, no tuvo acceso a los mapas, sino que solo a los datos referentes a la posición astronómica de los lugares que la expedición levantó a su paso por la gobernación de Chile. Incluso algunos de los valores dados para ciertos lugares, como Topocalma, resultaron discrepantes con los obtenidos por Gay, lo que provocó un cierto nivel de confusión en el naturalista, quien llegó a poner en duda los suyos, dado el prestigio que como astrónomos gozaban Felipe Bauzá y José Espinoza y Tello.

\section{Levantamientos cartográficos de Gay y Pissis}

Las autoridades de gobierno visualizan desde los albores de la República la imperiosa necesidad de disponer de información territorial confiable del espacio geográfico que les correspondía administrar. De ahí su afán por contar, entre otras cosas, con un inventario de los recursos disponibles en el territorio, con información sobre su extensión, distribución y localización de la población, ubicación de los recursos naturales, etc. Esta debía venir acompañada de su correspondiente representación cartográfica, es decir, de lo que hoy día solemos denominar cartografía topográfica y en la medida de lo posible de cartografía temática. De ahí que los primeros esfuerzos se orientaran a poder satisfacer la necesidad de una cartografía topográfica.

Durante el transcurso del siglo XIX se pretendió realizar dos levantamientos cartográficos completos del territorio nacional, fundados en mediciones científicas que contaron con el respaldo de las autoridades de gobierno, los que efectivamente cubrieron gran parte del territorio chileno. El primero es efectuado por el naturalista francés Claudio Gay, iniciado bajo el gobierno de José Joaquín Prieto, siendo Ministro del Interior Diego Portales, con quien Gay firma contrato el 14 de septiembre de 1830. En él se establece entre otros asuntos, la realización de una cartografía general de Chile y otra particular para cada una de las provincias en que se dividía el territorio nacional. El segundo es el encargado al geólogo y geógrafo francés Amado Pissis, contratado durante el gobierno de Manuel Bulnes, siendo Ministro del Interior Ca- 
milo Vial, con quien Pissis firma contrato el 10 de octubre de 1848. En dicho contrato se determina, la realización de un levantamiento geográfico y geológico de Chile.

Claudio Gay Ilega al puerto de Valparaíso a fines de 1828 junto a un grupo de jóvenes profesores franceses, con la finalidad de ser parte de un proyecto pedagógico, denominado Colegio de Santiago. El joven Claudio Gay había nacido en la localidad de Draguignan, Francia, en el año 1800. En 1830 , ante las dificultades de funcionamiento en las que se encontraba el Colegio de Santiago, Gay decide incursionar en otras actividades. Aprovechando su formación científica y técnica, presenta al Ministro del Interior un proyecto destinado a realizar una amplia investigación que contribuyera al conocimiento de la naturaleza del territorio en aspectos tan variados como flora, fauna, recursos minerales, suelo, clima. Todo esto lo fundamentaba bajo el argumento que era necesario para el país, diciendo en el documento en que ofrece sus servicios que: "no solamente por la riqueza de su suelo y la variedad de su clima, sino porque es un país desconocido absolutamente a los naturalistas" (Stuardo, 1973: 87). Tales fundamentos, en opinión de Sagredo, tienen una base real y efectiva, ya que expediciones como la de Alejandro Malaspina, realizada a fines del siglo XVIII que recogió antecedentes sobre la realidad del Chile colonial, permanecían desconocidos para el mundo científico. La expedición de Alejandro de Humboldt, que dio a conocer la realidad americana al mundo europeo, no alcanzó a reconocer la gobernación de Chile y, la expedición de Charles Darwin que en la década del 30 reconoció y recorrió el país, tenía objetivos muy diferentes a lo propuesto por Gay (Sagredo, 2004: 26).

La propuesta de investigación formulada por Gay se materializaría en una historia general y particular del territorio. Sin embargo, antes de su ejecución, fue sometida a la consideración de una comisión de hombres de ciencia y la autorización del Congreso de Plenipotenciarios, la que después de la evaluación correspondiente tuvo como resultado su aprobación. La comisión antes dicha, en su informe destacó la importancia que representaba para el país el asociar, a las ta- reas que realizaría el naturalista, el necesario conocimiento de la geografía del territorio. En atención a lo anterior, cuando se realizó la firma del contrato el 14 de septiembre de 1830, entre Claudio Gay y el ministro Diego Portales, se incluían también los trabajos geográficos, bajo el cual quedaba comprendida la realización de una cartografía del territorio nacional ${ }^{3}$.

3 Texto del Contrato. En: Stuardo O. Carlos. Vida de Claudio Gay, p. 91-93.

Artículo 1. D. Claudio Gay se obliga a hacer un viaje científico por todo el territorio de la República en el término de tres años y medio, con el objeto de investigar la Historia Natural de Chile, su Geografía, Geología, Estadística y cuanto contribuya a dar a conocer las producciones naturales del país, su industria, comercio y administración, y presentar al Gobierno, en el término de cuatro años por medio de una comisión que inspeccione sus trabajos, un bosquejo de las obras siguientes:

$1^{\text {a }}$ La Historia Natural general de la República que contenga la descripción de casi todos los animales, vegetales y minerales, con sus nombres vulgares, utilidades y localidades, acompañadas de una cantidad de láminas iluminadas proporcionada a los objetos que describa.

2a La Geografía física y descriptiva de Chile, con observaciones sobre el clima y temperatura de cada provincia; adornada de cartas geográficas de cada una, y de láminas de vistas y planos de las principales ciudades, puertos y ríos.

$3^{\underline{a}}$ La Geología, o sea un tratado de la composición de los terrenos, de las rocas, de los montes y de las minas que éstos contengan.

$4^{\text {a }}$ La Estadística general y particular de la República, con relación a la agricultura, industria, comercio, población y administración de cada provincia. $5^{\text {a }}$ Se obliga a formar un Gabinete de Historia Natural que contenga las principales producciones vegetales y minerales del territorio, y un catálogo en que predominen por sus nombres vulgares y científicos, y en que se demuestren los usos y utilidades de dichos objetos y los lugares donde se encuentran.

$6^{\text {a }}$ Se obliga a formar un catálogo de todas las aguas minerales del territorio, con sus análisis químicos y designación de los lugares en que se hallan.

Artículo $2^{\circ}$ A medida que D. Claudio Gay vaya avanzando en sus investigaciones sobre los diversos ramos mencionados, remitirá sus resultados a la comisión, la cual conservará en depósito y dará parte inmediatamente al Gobierno.

Artículo $3^{\circ}$ Siendo uno de los objetivos del Gobierno, al confiar esta importante comisión a D. Claudio Gay, dar a conocer las riquezas del territorio de la República, para estimular la industria de sus habitantes y atraer la de los extranjeros, D. Claudio Gay se obliga a publicar su obra tres años después de concluida su comisión.

Artículo $4^{\circ}$ En seguridad del cumplimiento de los anteriores artículos, D. Claudio Gay dejará en de- 
Amado Pissis Ilega a Chile en 1848 proveniente de Bolivia con destino a su patria, pero aquí el gobierno de la época le ofrece un contrato para hacerse cargo de la descripción geológica y mineralógica del territorio chileno. Esta obra estaría compuesta de un texto y mapas, lo que quedó estipulado en el contrato de seis puntos que firma con el Ministro del Interior Manuel Camilo Vial, el 10 de octubre de $1848^{4}$. Amado Pis-

pósito su biblioteca y sus colecciones de Historia Natural y dibujos, en casa de D. Francisco García Huidobro, pasando antes un inventario circunstanciado de dichos efectos: todo lo cual será propiedad del Estado y pasará a la Biblioteca Nacional si a juicio de la comisión D. Claudio Gay no va presentando resultados satisfactorios de sus trabajos después de seis meses contados desde la fecha de este contrata para adelante.

Artículo 5ํㅡㄹ Gobierno se obliga:

$1^{\circ}$ A dar a D. Claudio Gay durante el expresado término de tres años y medio que durará su viaje, ciento veinticinco pesos mensuales por semestres adelantados.

$2^{\circ}$ A pagarle por otros seis meses que se dilatará en perfeccionar los trabajos que ha de presentar al Gobierno en la forma que previene el artículo primero, ciento veinticinco pesos mensuales, pero no adelantados.

$3^{\circ}$ A proporcionarle los instrumentos que necesite para sus observaciones geográficas, quedando obligado D. Claudio Gay a devolverlos del mismo modo que los reciba, o su valor equivalente después de concluida la comisión.

$4^{\circ}$ A darle un premio de tres mil pesos, al menos, si cumple con lo que promete, previo el informe de la comisión, a no ser que por lo que toca a la parte estadística haya encontrado obstáculos insuperables, de que debe haber dado cuenta al gobierno.

$5^{\circ}$ A dirigir una circular a los Intendentes de las provincias para que sí, los Gobernadores de los pueblos y Jueces territoriales, faciliten a D. Claudio Gay todas las noticias de que necesite para el más puntual desempeño de la comisión.

Artículo 6ํㅡㄹ Esta contrata pasará al Excmo. S. Vicepresidente de la República para su aprobación; para que conste y tenga el debido cumplimiento, el infrascrito Ministro del Interior y D. Claudio Gay la firmaron en Santiago de Chile a catorce de septiembre de mil ochocientos treinta años. Diego Portales.- Claudio Gay.

4 Texto del Contrato. En: Greve, Ernesto. Don Amado Pissis, págs. $40-41$.

$1^{\circ}$ D. Amado Pissis se obliga a hacer la descripción geológica y mineralógica de la República de Chile, cuya obra se compondrá de texto y mapas. El texto lo dividirá en dos partes: una correspondiente a la geografía del país en que se indicará la posición geográfica, esto es, la latitud y longitud de las ciudades, pueblos, cerros y otros puntos notables, calculadas por observaciones astronómicas, sus alturas sobre el nivel del mar, y los demás elementos que sis nació el 17 de mayo de 1812, en Brioude, departamento del Haute Loire. Estudió en la Escuela de Minas de París y en 1830 ingresó a la Escuela Politécnica, donde se gradúa de ingeniero.

Como se desprende del contrato que firma Claudio Gay, dispondrá de un presupuesto destinado a la compra del instrumen-

deben servir de base a los mapas. Al formar esta parte el señor Pissis dedicará una particular atención a la Cordillera de los Andes que examinará del modo más prolijo que le sea posible, a fin de señalar con precisión el filo o línea más culminante que separa las vertientes que van a las Provincias Argentinas de los que se dirigen al territorio chileno, y la situación geográfica de los diversos bosques que permitan el paso por dicha cordillera a las varias provincias de la República.

La otra parte comprenderá la geología y mineralogía de Chile; y en ella se dará a conocer la composición geológica de cada provincia, y de todos los productos mineralógicos que se encuentren en ella y puedan ser útiles a algunas industrias, como la indicación exacta de sus asientos.

Los mapas serán el complemento y el resumen del texto, presentando al ojo la configuración exacta de cada provincia, la distancia de un punto a otro, sus alturas respectivas, la extensión de cada formación geológica, la posición de las minas y de todos los productos minerales útiles a las artes y agricultura.

2 A más de los pormenores que deben darse sobre la aplicación de los productos mineralógicos a la agricultura, el Sr. Pissis manifestará en una memoria adicional las mejoras agrícolas que fueren susceptibles los diversos terrenos que sean objeto de sus exploraciones, y los vegetales indígenas exóticos cuyo cultivo conviniere más en ellos.

$3^{\circ}$ Luego que D. Amado Pissis hubiere concluido sus trabajos sobre una o dos provincias, los presentará al Gobierno para su publicación. Los textos se escribirán en idioma francés; y el Gobierno los hará traducir de su cuenta al castellano, sometiéndose al examen de su autor, así como la publicación antes de imprimirse.

$4^{\circ}$ El gobierno de Chile abonará al Sr. Pissis un sueldo mensual de dos mil pesos y los gastos que hiciere en su traslación a los puntos que deba inspeccionar.

Le proporcionará asimismo un soldado que le ayude en sus exploraciones y una escolta suficiente, cuando tuviere que visitar lugares peligrosos.

5ํㅡㄹ Este convenio durará por el término de tres años forzosos para ambas partes; pero si los trabajos mencionados en los artículos $1^{\circ}$ y $2^{\circ}$ no se concluyeren en este término, el Sr. Pissis deberá continuar hasta su conclusión bajo las mismas condiciones de la presenta contrata.

6ํㅡㄹ término prescrito en el artículo anterior empezará a contarse desde esta fecha.

Santiago, octubre 10 de 1848.

Manuel Camilo Vial, Aimé Pissis. 
tal necesario para el levantamiento cartográfico comprometido; además deberá realizar un viaje por todo el territorio nacional para generar la historia natural del país y de cada provincia, con los correspondientes planos y láminas de las principales ciudades, puertos y ríos. El tiempo previsto para la ejecución de todo el trabajo era de tres años y medio.

En relación con el instrumental requerido para efectuar el levantamiento cartográfico, Claudio Gay aprovecha su viaje a Europa entre 1831 y 1834 , para encargarse personalmente de su compra; para ello dispuso de un presupuesto de $\$ 1.339$. Entre otros instrumentos, adquiere agujas para medir la declinación magnética, imanes, agujas para levantar planos (brújulas), sextantes, cronómetros, telescopios, barómetros, termómetros, higrómetros, eudiómetros, areómetros, un instrumento para observar la electricidad atmosférica y una cámara oscura.

Por su parte, del contrato firmado entre el gobierno chileno y Amado Pissis el 10 de octubre de 1848, se desprende que dos de sus artículos tienen directa relación con el encargo cartográfico recibido. En el primero de ellos se le encarga la realización de una descripción geológica y mineralógica de la República de Chile, el que deberá estar compuesto de una parte dedicada a la geografía del país y otra a la geología y mineralogía de Chile. Estarán complementados por mapas de cada provincia. Por el artículo cuarto, el Gobierno se compromete además de sus honorarios, a proporcionarle los instrumentos necesarios para la ejecución del levantamiento cartográfico. Con la finalidad de completar el instrumental indispensable para el levantamiento, Pissis adquirió también grafómetros (pantómetra), instrumento destinado a la medición de los ángulos en los vértices de menor importancia. Posteriormente, en Valparaíso compró en 1859, un cronómetro de marina, instrumento de mayor precisión e indispensable en la determinación de la longitud, y recomendó en 1860, comprar un círculo meridiano (universal) destinado a mediciones angulares y un círculo de reflexión.

Durante casi doce años, desde fines de 1830 hasta principios de 1842, Claudio Gay se ocupa de recorrer el territorio chileno desde el despoblado de Atacama hasta la Isla Grande de Chiloé. No obstante lo anterior, durante este tiempo realizó un viaje a Francia que le tomó más de 2 años, desde 1831 a 1834, con la finalidad de recopilar material y comprar el instrumental necesario para su trabajo, así como también un viaje al Perú, por algo más de 1 año desde 1839 a 1841, con el propósito de recoger información en los archivos peruanos sobre la historia y cartografía de Chile.

Luego de su trabajo de campo y con los antecedentes recolectados en el extranjero, el 29 de enero de 1841 Gay da a conocer la estructura de la obra y las temáticas que estarán consideradas en ella. Los temas que abordará serán la Flora chilena, Fauna chilena, Mineralogía y Geología, Física: terrestre y meteorológica, Estadística, Geografía, Historia, Costumbre y usos de los araucanos, mapas, planos y vistas. Con este material dará forma a su Historia Física y Política de Chile.

En relación con la cartografía que Claudio Gay compromete en su propuesta, ella comporta además del mapa general de la República, uno especial para cada provincia; añadiendo además un mapa de Geografía Física con más de 5.000 alturas de cerros y Ilanos; mapas geológicos, botánicos y zoológicos; una serie de planos de ciudades y puertos con algunas vistas y paisajes de Chile y un pequeño número de estampas relativas a las costumbres araucanas.

El caso de Amado Pissis es diferente al de Claudio Gay, ya que no hay una etapa de reconocimiento previo del país para formular el proyecto y su plan de trabajo en terreno. Una vez firmado el contrato, de inmediato inicia las operaciones geodésicas, actividad en la que ocupará la mayor parte de los dieciséis años que destinó a realizar el trabajo. Para cumplir con lo solicitado, recorre el país desde el desierto de Atacama hasta los inicios de la región de la Araucanía.

En la propuesta de trabajo hecha al gobierno por Claudio Gay en 1841, que como se dijo anteriormente, se hizo después de haber firmado contrato y recorrer el territorio nacional, se compromete a ocuparse de diferentes temáticas que respondían a su 
condición de naturalista. También plantea satisfacer la solicitud hecha en cuanto a proporcionar documentación cartográfica confiable del territorio chileno, la que se hacía indispensable en un momento en que el país se encontraba en plena etapa de organización política y administrativa. Por lo que respecta a Amado Pissis, es el gobierno el que demanda sus servicios, formulándole una petición específica y concreta en 1848, por la que se le solicita que realice el levantamiento de un plano topográfico y geológico de Chile, demanda que está acorde con su formación de geógrafo y geólogo. Con todo, resulta curioso que aunque tal solicitud del gobierno a Pissis puede responder por una parte, a mejorar lo iniciado por Gay, también es posible encontrar por otro lado, una explicación proveniente del hecho que habiendo transcurrido un tiempo prudente para la entrega de la cartografía comprometida por él, esta se dilataba más de lo conveniente para su finalización, puesto que no tiene otra explicación el hecho que mientras Claudio Gay se encuentra en Francia, abocado a la redacción final de su trabajo y elaboración e impresión de la cartografía, el gobierno chileno contrate a otra persona para realizar una tarea similar en lo cartográfico (Gangas, 1985b: 51). Habría que añadir sí, que estaba considerado un nuevo aspecto en el contrato con Pissis, como era disponer de un conocimiento lo más real posible de los recursos geológicos y mineralógicos que ofrecía el territorio y la localización de estos, asunto de primera importancia en otro momento dentro de la evolución del país, vinculado ahora con el desarrollo económico de la nación.

Claudio Gay para dar cumplimiento a la realización de la cobertura cartográfica que inicia en 1834, luego de su regreso de Francia y una vez que ya dispone del instrumental necesario para el levantamiento, determina como metodología de trabajo lo siguiente: para recoger la información de cada lugar que se visite, se deberá proceder a fijar con exactitud la localización de los puntos geográficos seleccionados, entendiendo por esto, determinar: latitud, longitud y altitud, con la finalidad de reunir así el mayor número de datos, para facilitar tanto el levantamiento del mapa general del territorio como los particulares de cada provincia.
Como quedó anteriormente establecido, el método imperante para los levantamientos cartográficos entre los cartógrafos era el de la triangulación geodésica, método que también había mostrado su eficacia en la determinación de la magnitud del arco de meridiano entre Dunkerque y Barcelona, realizado por J.B.J. Delambre y P.F.A. Méchain, entre 1792 y 1799 , cuya medición permitió establecer el metro como unidad de medida universal. Sin embargo, Claudio Gay, a pesar de conocer las bondades del método en cuanto al mayor grado de precisión que este otorgaba a los levantamientos cartográficos, también estaba consciente que su aplicación demandaría demasiado tiempo, sobre todo teniendo en cuenta que la tarea de levantar la cartografía del país era una más dentro de todos los aspectos que debía cumplir por contrato. Así se lo hace saber al Presidente de la República Pedro Montt en carta fechada el 15 de septiembre de 1856, cuando le manifiesta lo siguiente: "Puesto que hablo de Geografía, permítame decirle algunas palabras con motivo de mis cartas geográficas, las cuales fueron emprendidas al principio con todo el cuidado de que era capaz; pero pronto me di cuenta de que este trabajo me exigía un tiempo extremadamente largo y con gran perjuicio de mis otras investigaciones, entonces creí de mi deber contentarme con hacer mis levantamientos con la brújula, observando a distancia algunas latitudes para mis coordenadas. Estaba tanto más convencido cuanto que este medio era, en esa época, el único que yo tuve que seguir, que por más que mis mapas hubieran sido de la mayor exactitud, no habría impedido al gobierno hacerlos recomenzar cuando las necesidades administrativas lo hubieran exigido: uno para la administración del catastro o para los reconocimientos militares"(Feliú, 1973: 45).

Lo señalado anteriormente por Gay está íntimamente relacionado con el resultado final de su producto cartográfico, en virtud que el método que él aplica en su levantamiento, será determinante a la hora de establecer las deficiencias que presenta su cartografía, en cuanto a la precisión del trazado del litoral, la ubicación de centros poblados, diseño del curso de ríos, contorno de lagos y ciertamente, la indefinición del tra- 
zado del límite oriental del país. Por otra parte, en mérito de su trabajo, "es importante señalar que Claudio Gay no contó con personal especializado como ayudantes de campo, más bien eran empleados de servicio" (Gangas, 1985a: 175).

Por su parte, Amado Pissis utiliza, como método para ejecutar su levantamiento cartográfico la triangulación geodésica. Como se señaló anteriormente, la aplicación de dicho método requiere de la medición de líneas de bases. Por otro lado, cuando la triangulación comprende una gran extensión territorial, es necesario construir unos pilares de albañilería en cada vértice principal escogido, acompañándola de una demarcación subterránea destinada a perpetuar el punto demarcado, se agrega también una señal de cierta altura que puede decirse, materializa la vertical en caso de no usarse señalización luminosa como son los heliotropos, aparato que utilizan los rayos solares. Pissis establece para la realización de su trabajo cinco líneas de base: la de Santiago, que sirve de punto de partida, una en la provincia de Atacama, otra en la provincia de Coquimbo y dos más en las provincias de Talca y de Arauco. La longitud de las cinco líneas de bases que fueron medidas, alcanzaron magnitudes entre los 700 y 2.000 metros (Medina, 1889: CXXII). Como complemento de lo anterior, también realiza numerosas observaciones astronómicas, tanto para verificar los azimutes (ángulos) de los lados de los triángulos como para las latitudes de todas las ciudades, villas y pueblos que visita en sus recorridos por el país.

No obstante, en un informe presentado al Ministro del Interior, Pissis justificaba no ajustarse plenamente a lo señalado previamente, diciendo lo siguiente: "He tenido que abandonar desde el principio el uso de las señales artificiales, cuya construcción sería una carga onerosa para el Estado y suplir esta falta por numerosas verificaciones a fin de que no quedara ninguna incertidumbre sobre la exactitud de los resultados", para añadir más adelante que "el conjunto de los trabajos tal como resulta de las últimas operaciones, consta de una serie de triángulos secundarios que sirven a (para) relacionar los demás puntos de territorio, así es que las posiciones geográficas de todos los puntos notables han podido calcularse directamente y de un modo del todo independiente de las observaciones astronómicas" (Greve, 1946: 78).

La triangulación de Pissis, una vez finalizada, quedó compuesta por 67 triángulos que cubrían el país desde el desierto de Atacama hasta el principio de la Araucanía. Inicia sus actividades en 1848 y finaliza en 1865, para lo cual dispuso en teoría con varios ayudantes que le colaboraron tanto en su trabajo de campo como de gabinete, personal que contaba con una formación acorde al trabajo a realizar. Algunos de sus colaboradores eran astrónomos y otros agrimensores, aunque no siempre fue posible disponer de ellos; incluso, en ocasiones debió trabajar solo, en atención a que varios de ellos después de algún tiempo, emigraban hacia trabajos mejor remunerados ${ }^{5}$. Por otra parte, en estos dieciséis años, no estuvo siempre dedicado a las operaciones geodésicas que implicaron la realización de las trece hojas del plano topográfico y geológico, a escala de 1:250.000, sino que también debió atender otros encargos de carácter oficial. Las once primeras hojas del plano topográfico, tienen como base triangulaciones de primer orden, por lo que las otras dos hojas correspondientes a las provincias de Valdivia y Llanquihue, solo tienen como base mediciones astronómicas ${ }^{6}$.

5 Greve, Ernesto. En: Don Amado Pissis, p. 67-77, cita entre los colaboradores de Pissis al astrónomo Carlos Guillermo Moestra, al ingeniero Luis de Bresse, al capitán de ingenieros José Antonio Donoso Fantoval y los tenientes Félix Blanco Gana y Alberto Blest Gana, al ingeniero civil Alcibíades de la Plaza, los agrimensores José Rafael Velasco, Marco Silva, Francisco Salas y Ramón Picarte, el agrimensor Gabriel Izquierdo, el ingeniero en minas Pedro Lucio Cuadra, el astrónomo Arminio Volckmann, los ayudantes Teófilo Mostardi y Martín Drouilly, el ingeniero geógrafo Enrique Concha y Toro, el astrónomo Ricardo Schumacher y el ingeniero de minas Augusto Villanueva García.

6 Las mediciones que forman parte de una triangulación geodésica denominadas de "primer orden", son aquellas que tienen el más alto nivel de precisión dentro de un levantamiento cartográfico y, son las que sirven de puntos de apoyo para las demás mediciones que comporta el levantamiento. Por su parte, las de "segundo orden" y las mediciones astronómicas son de menor precisión. 
El mapa de Pissis a escala 1: 250.0000, se extiende desde el paralelo 27 hasta el grado 42. Para la parte norte, desde el paralelo 27 hasta el límite con Bolivia, debió basarse en otros trabajos para completarlo. A su vez, para la parte localizada al sur de Arauco, sector ocupado por los indígenas, así como también las provincias de Valdivia, Chiloé y Magallanes, debió recurrir solo a observaciones astronómicas y triangulaciones de segundo orden, junto a otras fuentes como la cartografía elaborada por Claudio Gay.

En 1864 Pissis, para justificar el porqué ha hecho solo mediciones astronómicas y no una triangulación geodésica de primer orden en el área ubicada al sur de la frontera araucana, manifiesta que: "este territorio se hallaba muy poco poblado; y que los espesos bosques que cubrían la mayor parte del sur de Chile no le permitieron seguir con sus triangulaciones más allá del grado 38; y de ahí que para levantar el plano del territorio que se extiende hasta el paralelo 42, fue necesario basarse en la determinación de coordenadas geográficas, estableciendo al efecto un pequeño observatorio temporal en la ciudad de Valdivia y otro de la misma índole en Puerto Montt, completando el trabajo a base de pequeñas triangulaciones parciales, por lo que no se justificaba que la costosa topografía detallada pudiese presentar un interés de acuerdo con los gastos" ${ }^{7}$ (Greve, 1946: 43).

Dada las características que presenta el relieve del territorio chileno, la medición de las altitudes es de suma importancia para mostrar fielmente sus diferentes geoformas, representadas en este caso por las planicies litorales, la cordillera de la costa, la depresión intermedia y la cordillera andina, por lo que Pissis trató de reunir la mayor cantidad de medidas de estas unidades de relieve en su trabajo de terreno. Para su cumplimiento explica que "las altitudes de los puntos trigonométricos, lo mismo que las cumbres más notables de la cordillera de los Andes, han sido calculadas por medio de numerosas distancias cenitales, y para los casos en

7 Informe del 21 de junio de 1864 de Amado Pissis al Ministro del Interior, don Alvaro Covarrubias. que este método no podía aplicarse, se ha hecho uso de las observaciones barométricas combinadas de tal modo que la exactitud de los resultados puede compararse a la que se obtiene por medio de las operaciones trigonométricas" ${ }^{\prime 8}$ (Greve, 1946: 42).

Respecto a las dificultades que presenta el relieve de la cordillera de los Andes, para determinar los rasgos topográficos más específicos de la cordillera mediante el método de la triangulación, Pissis dice que: "toda esta parte del trabajo está basada exclusivamente sobre observaciones astronómicas. Las latitudes y longitudes de todos los puntos notables de los ríos, como los puntos de inflexión y las juntas de los afluentes, han sido fijados por este método; en fin, la dirección de algunas gargantas en las cuales no ha sido posible penetrar, se ha deducido de las direcciones de los cordones que forman las vertientes" (Pissis, 1860: 17).

De acuerdo a lo que manifiesta Pissis en los diversos informes y la correspondencia que se ha señalado precedentemente, en relación con la imposibilidad de aplicar la triangulación para efectuar mediciones de primer orden y reemplazarlas por las de segundo orden o simplemente por mediciones astronómicas; así como también la falta de construcción de pilares para perpetuar los puntos del terreno escogidos para la triangulación, junto a la forma de establecer la altitud de los puntos culminantes de la cordillera, lo que unido a la manera de definir la dirección de los cordones montañosos o el curso de los ríos, son todos asuntos que incidirán de manera significativa en el nivel de precisión del producto cartográfico que finalmente generó, el que será objeto de múltiples críticas.

\section{Productos cartográficos generados por Claudio Gay y Amado Pissis}

En 1842, Claudio Gay se instala en París con el propósito de buscar colaboradores

\footnotetext{
8 Informe sobre los trabajos de la comisión topográfica presentado al señor Ministro del Interior, don Alvaro Covarrubias, 21 de julio de 1865.
} 
para la redacción de su trabajo, coordinar la entrega de materiales para su impresión y finalizar la elaboración de la cartografía. Sin embargo, en carta de octubre de 1842 Gay, se excusaba ante el ministro Montt de no haber podido cumplir con la promesa que durante su viaje de regreso a Francia, se ocuparía "de la conclusión de los mapas, para poder publicarlos a su llegada a París, lo cual no había sido posible por haberse sentido indispuesto durante la navegación". En definitiva, la cartografía comprometida por Gay no estaba aún finalizada, dado que había tenido que preocuparse de atender otros asuntos, especialmente lo relativo al tema del financiamiento de la obra, añadiendo más adelante en su misiva que la confección de la cartografía le resultaba tedioso porque: "además de lo ingrato exige tanta precisión" 9 .

La urgencia y premura con la que el gobierno requería la cartografía, queda de manifiesto en la respuesta que Claudio Gay le da al ministro Manuel Montt en mayo de 1843, en atención a que todavía en esta fecha aún no se disponía de ella, dándole como solución a la solicitud que hacía el ministro de la cartografía que "mientras tanto, el Supremo Gobierno puede hacer uso de lo que he dejado en el ministerio de US, pues es bastante exacta y más que suficiente para cualquier operación administrativa" ${ }^{10}$.

En marzo de 1844, cuando aparece el primer cuadernillo de la obra con 130 páginas, Gay hace llegar un ejemplar al Presidente de la República en el mes de mayo de ese mismo año y aprovecha la oportunidad para explicarle que todavía no había concluido el trabajo de los mapas, los que con tanta urgencia le solicitaba el gobierno.

Hay que hacer presente que en el momento que Gay inicia definitivamente su trabajo de terreno en 1834, la división política administrativa imperante dividía al país en diez provincias: Coquimbo, Aconcagua, Val-

\footnotetext{
9 Carta al Ministro de Justicia e Instrucción Pública don Manuel Montt, París, octubre de1842 (Sagredo, 2004: 29).

${ }^{10}$ Carta al Ministro de Justicia e Instrucción Pública don Manuel Montt, París, mayo de 1843 (Sagredo, 2004: 29).
}

paraíso, Santiago, Colchagua, Talca, Maule, Concepción, Valdivia y Chiloé, pero en el instante en que Gay se instala en París en 1842, para dar inicio a su trabajo de gabinete y confección de la cartografía, se había agregado la provincia de Atacama, cuya fecha de creación corresponde al año 1843. No obstante, él había alcanzado a recorrerla en 1842 luego de su regreso del Perú, de ahí que las cartas particulares destinadas a representar cada una de las provincias para estructurar su atlas, este muestra un total de once provincias en la que se incluye Atacama. Entre estas once provincias se encuentra una con el nombre de "provincia de Cauquenes", la que oficialmente nunca existió, cuya área territorial corresponde al de la "provincia del Maule". Sin embargo, esta situación es corregida en el mapa general de Chile que acompaña a su obra "Atlas de la Historia Física y Política de Chile", publicada en París en 1854. Este mapa general de Chile muestra la división político administrativa que impera en ese momento en el país, el que está dividido ahora en doce provincias, a raíz que entretanto se había creado en 1848, una nueva unidad política administrativa, la "provincia de Ñuble". Como se aprecia por lo señalado anteriormente, era un momento de constantes cambios en lo relativo a la organización político administrativa del Estado, producto de los requerimientos de una nación que está en la búsqueda de planificar y ordenar de manera eficiente su espacio geográfico. De esta manera se responde también a las constantes demandas de orden político, económico y social que normalmente existen en la creación de las nuevas unidades administrativas en el país.

En definitiva, la producción cartográfica de Claudio Gay está compuesta por un mapa general de Chile denominado "Mapa para la inteligencia de la historia física y política de Chile", a escala 1:2.000.000 aproximadamente, que abarca entre las latitudes $25^{\circ}$ y $44^{\circ}$ Sur y, un conjunto compuesto por 12 mapas particulares que representan las provincias de Chile a escalas que varían entre 1: 800.000 y $1: 1.500 .000$. De acuerdo con las escalas utilizadas para su confección y los elementos naturales y culturales que se muestran en ellos, están dentro de la categoría de mapas físicos. 
Por su parte, la producción cartográfica de Pissis está compuesta por 13 hojas que dan forma al "Plano Topográfico y Geológico de la República de Chile" a escala 1: 250.000 , conjunto que cubren desde los $27^{\circ}$ $18^{\prime}$ S. hasta los $41^{\circ} 58^{\prime} \mathrm{S}$. Por la escala en que está confeccionada esta cartografía, corresponde en verdad a una carta topográfica. Completa su obra un "Mapa de la República de Chile desde el río Loa hasta el cabo de Hornos" a escala 1: 1.000.00011.

El trabajo de Pissis materializado en el "Plano Topográfico y Geológico de Chile" a escala 1: 250.000, tendría tres ediciones: La primera, correspondería a una prueba relativa a las diez primeras hojas conteniendo la planimetría, hidrología, límites geológicos, faltándoles enteramente la representación de la orografía. La segunda, corresponde a la impresión en negro de trece hojas grandes, con la representación orográfica y finalmente la tercera, corresponde a la colección impresa, como la anterior en negro, pero a la cual se ha colocado a mano quince diferentes colores representativos de los diversos tipos de terrenos geológicos (Greve, 1946: 16).

En 1867 fueron presentadas por parte de Pissis, una serie de siete cartas al Supremo Gobierno, las que abarcaban desde la provincia de Atacama hasta la de Ñuble y grabadas por Narciso Desmadryl. Con anterioridad, el 18 de agosto de 1866 Amado Pissis había declarado que el trabajo de terreno y el dibujo había llegado a su término para once de las hojas correspondientes a las provincias de Atacama, Coquimbo, Aconcagua, Valparaíso, Santiago, Colchagua, Talca, Maule, Ñuble, Concepción y parte de Arauco. Por su parte, las operaciones de levantamiento de las provincias de Valdivia y Llanquihue fueron hechas durante los años

\footnotetext{
11 El Instituto Panamericano de Geografía e Historia (IPGH), postula la denominación de plano para las representaciones cartográficas que utilizan escalas desde 1: 1 hasta 1:25.000, que corresponde a escalas grandes; cartas para escalas desde 1:25.000 hasta 1: 250.000, que corresponde a escalas medianas y mapas para todas aquellas representaciones que utilizan escalas superiores a 1:250.000, correspondiéndole la denominación de escalas pequeñas.
}

1866-67 y 1867-68, respectivamente, pero el sector ocupado por los araucanos fue copiado de antiguos mapas existentes.

El "Plano Topográfico y Geológico de la República de Chile", a la escala 1:250.000, fue presentado, en su colección completa y, por tanto, con el achurado representativo del relieve orográfico al Congreso Internacional de Geografía celebrado en la ciudad de Venecia el año 1881. El capitán Jorge M. Wheeler, comisionado norteamericano al congreso, dice de la cartografía de Pissis lo siguiente: "El gobierno de Chile estableció, en 1849, una Comisión Topográfica con A. Pissis como jefe o director, agregando a sus obligaciones el encargo de hacer, al mismo tiempo, un examen geológico. En 1870 el trabajo tenía un grado de avance tal que el mapa, en trece hojas, fue puesto, para ser grabado, en manos de N. Desmadryl, en París; y en 1873 fue editado bajo el título "Plano Topográfico y Geológico de la República de Chile, levantado por orden del Gobierno, bajo la Dirección de A. Pissis", escala 1 : $250.000^{\prime \prime 12}$

En 1876, cuando Amado Pissis asume como Jefe de la Sección de Geografía de la Oficina Central de Estadística, se ocupó de la confección de un mapa geográfico general de todo el país a escala 1: 1.000.000, recurriendo a la información que él había recolectado para su mapa escala 1: 250.000. Para la parte austral, se vale de las cartas náuticas, originadas tanto por los servicios nacionales como extranjeros. Fue grabado en la casa Pedro Cadot y Cía., en quince hojas de 52 por 35 centímetros y dado a luz, sin indicación de año de publicación, bajo el siguiente título "Mapa de la República de Chile desde el río Loa hasta el cabo de Hornos, por A. Pissis. 1: 1.000.000"13.

\footnotetext{
12 Informe del comisionado norteamericano capitán J.M. Wheeler al Congreso Internacional de Geografía, Venecia 1881(Greve, 2004: 61).

13 En relación con el año de publicación de este mapa general de Chile, Alejandro Bertrand estima que el año de publicación sería 1884-1885, para Ernesto Greve sería 1888, por el hecho de figurar el Departamento de Taltal cuya delimitación norte fue considerada en la creación de la provincia de Antofagasta, la cual fue creada por ley el 12 de julio de 1888.
} 
En relación con este mapa, Pissis dice lo siguiente: "se extiende desde el grado 24 de latitud sur hasta el Cabo de Hornos y por el lado Este hasta la costa del Atlántico desde el río Santa Cruz. Para formar este plano me he servido del levantado por la comisión topográfica entre los grados 27 y 42, haciendo las adiciones que corresponden a las nuevas líneas férreas así como a las divisiones administrativas. La parte incluida entre los grados 24 y 27 se ha formado mediante los datos que había reunido en mis dos exploraciones del desierto de Atacama. Por fin, para la parte situada al Sur del grado 42 he consultado los trabajos de Fitzroy, los del capitán Mayne y los de los oficiales de la marina de Chile. Concluido este trabajo, he pensado que sería útil formar otro plano a la misma escala de la parte fronteriza del desierto de Atacama, valiéndose de los numerosos puntos cuya posición había sido fijada durante la comisión que el Gobierno tuvo a bien confiarme con el objeto de fijar los paralelos de los grados 23, 24 y 25 . Este plano se extiende desde el grado 24 hasta el río Loa y forma así la continuación del plano general de la República"14.

Tanto el levantamiento cartográfico de Claudio Gay como el de Amado Pissis, fueron objeto de elogios así como también de críticas. Los elogios estaban orientados a destacar el valor que significaba el poder contar con una herramienta de esta naturaleza para las necesidades de ordenamiento, planificación del territorio, localización y disponibilidad de los recursos naturales. Las críticas se dirigían a hacer presente las deficiencias que se detectaban en las representaciones: nivel de precisión en la ubicación de los fenómenos y localización de objetos presentes en el territorio, así como la calidad de la información entregada. Ambos hechos están en directa relación con la forma como se aplicaron los diferentes métodos utilizados en el trabajo de campo, es decir, la triangulación geodésica y las mediciones astronómicas, las que a su vez responden, a la rigurosidad con que se utilizaron los instrumentos para obtener información y la

\footnotetext{
14 Pissis, Amado. Informe sobre los trabajos de la Oficina de Geografía, desde Junio de 1877 hasta Junio de 1879. Santiago, mayo 28 (Greve, 2004: 68).
}

preparación del personal a cargo de estas operaciones en el terreno y su posterior trabajo en el gabinete.

El sabio francés Boussingault, al comentar la obra cartográfica que Claudio Gay presentaba en los círculos científicos franceses decía: "no puede exigirse que un viajero, por más hábil que se supone, levante solo un Mapa de una comarca extensa con la misma precisión que emplearía en esta operación un cuerpo de ingenieros. El tributo que paga el viajero a la ciencia geográfica, es ordinariamente un bosquejo, cuya importancia de todo punto relativa, depende principalmente de la escasez de documentos más exactos; sus noticias no comprenden por lo regular más que simples reconocimientos del terreno que, a pesar de todas sus imperfecciones, son sin embargo de grande interés, en cuanto ellas indican de una manera general la dirección de las cadenas de cerros, la posición y extensión de los grandes valles, el curso de los ríos; en una palabra, ellas satisfacen a las primeras necesidades de la geografía física. Sin duda trabajos ulteriores rectificarán o añadirán muchos detalles; la posición de tal ciudad, de tal afluencia de un río será colocada algunos minutos más o menos distante del meridiano; pero por lo regular estas adiciones o rectificaciones no modifican el conjunto" ${ }^{15}$.

En opinión de Alberto Edwards, la cartografía realizada por Gay se "trata de un mapa de nuestro territorio, rico en detalles y que revela un notable sentido topográfico de parte de su autor. Este trabajo no está basado en ninguna operación trigonométrica, ni siquiera preliminar, y no pasa de ser un croquis trazado más o menos a ojo, quizás auxiliándose con la brújula y con algún aparato para medir distancias". Agrega que "el contorno marítimo del territorio es lo menos imperfecto de este trabajo, pues, el señor Gay pudo en esta parte auxiliarse con los estudios hidrográficos ya efectuados en su tiempo; sin embargo, los detalles de la costa aparecen trazados en forma caprichosa, aún en sus sectores mejor conocidos en aquella

\footnotetext{
15 Anales de la Universidad de Chile, 1858 (Greve, 2004: 11).
} 
época", para finalmente concluir que "con todo, el mapa de Gay, sirvió, por lo que respecta al interior del territorio, de base a todas las publicaciones cartográficas de carácter general, aparecidas antes del mapa de Pissis. No es necesario agregar que hoy la obra geográfica de Gay no tiene sino un interés histórico: creemos pues inútil insistir sobre ella" (Edwards, 1911: 51).

En cuanto a la obra de Pissis, en 1873, el Ministerio del Interior al acusar recibo de la cartografía que envía desde París, le Ilama la atención el hecho que en las colecciones coloreadas faltaba, con tal característica, la número once, a lo cual Pissis contestó que "esta hoja corresponde a la parte del territorio ocupada por los indios rebeldes y en la cual no ha sido posible penetrar. El gobierno no queriendo dejar este vacío entre las provincias de Arauco y Valdivia, me encargó hacer un plano provisorio con los datos que podría reunir, por lo que esta parte quedó sin indicaciones geológicas por falta de datos ciertos y no pudo colorearse" ${ }^{\prime 16}$.

Por otro lado, en opinión de Alberto Edwards, el trabajo de Pissis tuvo sin merecerlo una influencia considerable, desde su publicación por los años 1872, en desmedro de otros esfuerzos, ya que durante casi un cuarto de siglo, todo cuanto se publicó a este respecto sobre Chile, tenían como base la cartografía elaborada por el ingeniero francés. Esta situación se explica en cierta medida, por el hecho que Pissis presentó su mapa como el resultado de una triangulación geodésica, que cubría todo el territorio de la República, desde Copiapó, hasta la frontera araucana. Edwards continúa diciendo que, si la base técnica era de grandes pretensiones, la ejecución no lo fue menos, dado que el mapa se publicó en una escala grande 1: 250.000, para sentenciar que por el número de detalles que contenía apenas habría justificado un mapa de escala 1 : 1.000.000. Por otra parte, indica que la pretendida triangulación geodésica era deplorable. Un simple trabajo preliminar puramente topográfico, habría sido declarado inservible, con una aproximación muy superior a

16 Archivo Nacional. Legaciones y consulados 1958 1873 (Greve, 2004: 45). la que alcanzó Pissis. Fundamenta su opinión en lo dicho por el ingeniero Alejandro Bertrand, en el informe dedicado al trabajo de Pissis sobre la formación del Plano Topográfico en el que dice que: "Ios lados de los triángulos de primer orden, en la región más poblada y central del país, presentan errores que fluctúan entre el 8 y 43 por ciento del largo total. Si esto sucede con el cánevas fundamental de la obra de Pissis, ya se comprenderá el valor de los detalles"17.

Edwards, al continuar con su crítica al mapa de Pissis dice que "esta tentativa prematura y fracasada, de realizar un levantamiento geodésico completo del territorio de la República, había perjudicado extraordinariamente nuestros progresos geográficos. Un mapa hecho a brújula y podómetro por cualquier individuo medianamente sensato y discreto, aprovechando las cartas hidrográficas y las posiciones astronómicas conocidas, no habría sido muy inferior, al levantamiento geodésico de Pissis, con la ventaja de no haber engañado a los geógrafos, al Gobierno y al público. Las personas familiarizadas con el mapa de Pissis opinan que en los detalles es inferior al de Gay; que en la estructura general contiene errores de tal naturaleza, que no pueden explicarse, sino por la pérdida de las libretas de trabajo, que el ingeniero francés debió después reconstituir de memoria ó con la ayuda de apuntes dispersos". Finalmente dice que, "dados estos antecedentes es lamentable que existan todavía secciones de nuestro territorio, y que esto en su parte más importante y poblada, para las cuales no poseemos otros documentos que el mapa de Pissis. Felizmente estas zonas no son muy extensas y se encuentran rodeadas por todas partes de terrenos mejor conocidos, lo que ha permitido rectificar los errores más considerables" (Edwards, 1911: 53).

José Toribio Medina al comentar también en 1889 la obra cartográfica de Pissis dice: "Es fácil comprender que un trabajo de esta naturaleza ni queda desde luego completo ni puede tampoco dejar de adolecer de errores de alguna consideración; pero tal como

\footnotetext{
17 Bertrand, Alejandro. Memoria acerca de la formación del Plano Topográfico de Chile, Santiago, 1895 (Edwards, 1911).
} 
es puede asegurarse que es el mejor de los de su clase levantado hasta ahora en la América del Sur, y que el país y el gobierno que lo inició y los que lo fomentaron después pueden sentirse legítimamente satisfechos" (Medina, 1889: CXXVI).

Ernesto Greve, por su parte, critica la forma como Pissis resolvió ciertas situaciones en la confección del "Plano Topográfico y Geológico de la República de Chile", a la escala de 1: 250.000, del año 1873, como aquello de deducir, a partir de la red hidrográfica los detalles correspondientes a la orografía o bien la orografía a partir de la red hidrográfica, cuando las condiciones del terreno no facilitaban su inspección directa, ya que Pissis dice que: "en aquellos lugares donde no ha sido posible penetrar, la dirección de los cordones, se han deducido de las direcciones de los cordones que forman las vertientes" ${ }^{\prime 18}$. Sin embargo, más adelante agrega Greve que "con los errores o defectos demostrados en diversas ocasiones, o los que en el puedan haber pasado aún desapercibidos, tuvo gran importancia para la fijación de los límites administrativos" (Greve, 1946: 19).

Con todo, el legado cartográfico dejado por Claudio Gay, tanto por la carta general del país, como las particulares de cada provincia, se constituye en una herramienta básica para la administración y ordenación del territorio, en el momento que la República buscaba iniciar un ordenamiento de su organización interior fundada en un conocimiento real y efectivo del espacio geográfico perteneciente a la nación chilena. De ahí que contar con ella, a pesar de las deficiencias que la cartografía presenta, implicó el haber dado un paso de suma importancia en el acopio de información territorial, en el que se fundaron posteriormente variadas decisiones espaciales que el gobierno central pudo tomar con conocimiento de causa.

Por su parte, de los productos cartográficos que se derivan del trabajo realizado por Amado Pissis, habría que diferenciar cuando

\footnotetext{
18 Amado Pissis. "Descripción topográfica y geológica de la provincia de Colchagua" (Greve, 2004:.17).
}

se habla del mapa a escala 1:250.000 o del confeccionado a escala 1: 1.000.000. En lo concerniente al primero de ellos, confeccionado en una escala mediana, donde el nivel de detalle de la información que debe contener una representación de esta naturaleza debe ser proporcional a la escala, es claro que no cumplió con este requerimiento, lo que se refleja en lo reducido de la toponimia que registra la carta. Lo mismo se puede decir en cuanto a su nivel de precisión en la localización de los fenómenos geográficos, críticas que se sustentan principalmente en haber tratado de ejecutar un levantamiento fundado en una triangulación geodésica de primer orden que no fue posible cumplir, por lo que la precisión lograda se vio seriamente comprometida. En cambio su mapa al millonésimo, que a pesar que se elaboró a partir de la base proporcionada por el 1: 250.000, es mejor valorado; entre otras cosas, por estar confeccionado a una escala pequeña donde el nivel de detalle que se exige es menor y por lo tanto, la información es más generalizada, lo que contribuye a que las deficiencias que pudiese contener, en cuanto a precisión en la localización de los accidentes del terreno son menos notorias, además, el mismo Pissis manifiesta que fue mejorado con nueva información proveniente de levantamientos ejecutados muy próximos a la fecha de su publicación en 1888. Todo lo anterior, lo hace calificar como un mapa de buen nivel.

\section{Características cartográficas de las cartas y mapas de Gay y Pissis}

La proyección utilizada por Claudio Gay para la confección del mapa general de Chile corresponde a una de tipo equivalente, es decir, aquellas que guardan correctamente la superficie de los territorios representados, con una división entre paralelos y meridianos cada $1^{\circ}$ y estos segmentados cada $12^{\prime}$. Este mapa tiene adicionado en un recuadro, en su parte inferior derecha, un mapa de América meridional muy similar al realizado por la expedición de Alejandro Malaspina para esta parte de América. Los mapas específicos de cada una de las 12 provincias consideradas en su obra, están confeccionados sobre proyección de Mercator, proyec- 
ción de tipo conforme, es decir, que guarda correctamente la forma del terreno representado, con una graduación en latitud y longitud cada un grado sin subdivisión. El meridiano base o cero, que utiliza Gay como referencia para determinar la longitud geográfica es el de Cádiz. Por otra parte, la escala elegida para el mapa general es 1 : 2.000.000 aproximadamente, en que se indica la división provincial y departamental del país. Los mapas provinciales están confeccionados a escalas que varían entre 1 : 800.000 y $1: 1.500 .000$, con su correspondiente división departamental (Figura № 3).

Claudio Gay para la representación del relieve chileno en sus mapas, elige como método el denominado de las "normales", en este caso con sombreado vertical, de uso más común y menos engorroso que el

Figura $N^{\circ}$ 3

MAPA DE LA PROVINCIA DE CONCEPCIÓN QUE FORMA PARTE DEL ATLAS DE LA HISTORIA FÍSICA Y POLÍTICA DE CHILE, LEVANTADO POR CLAUDIO GAY

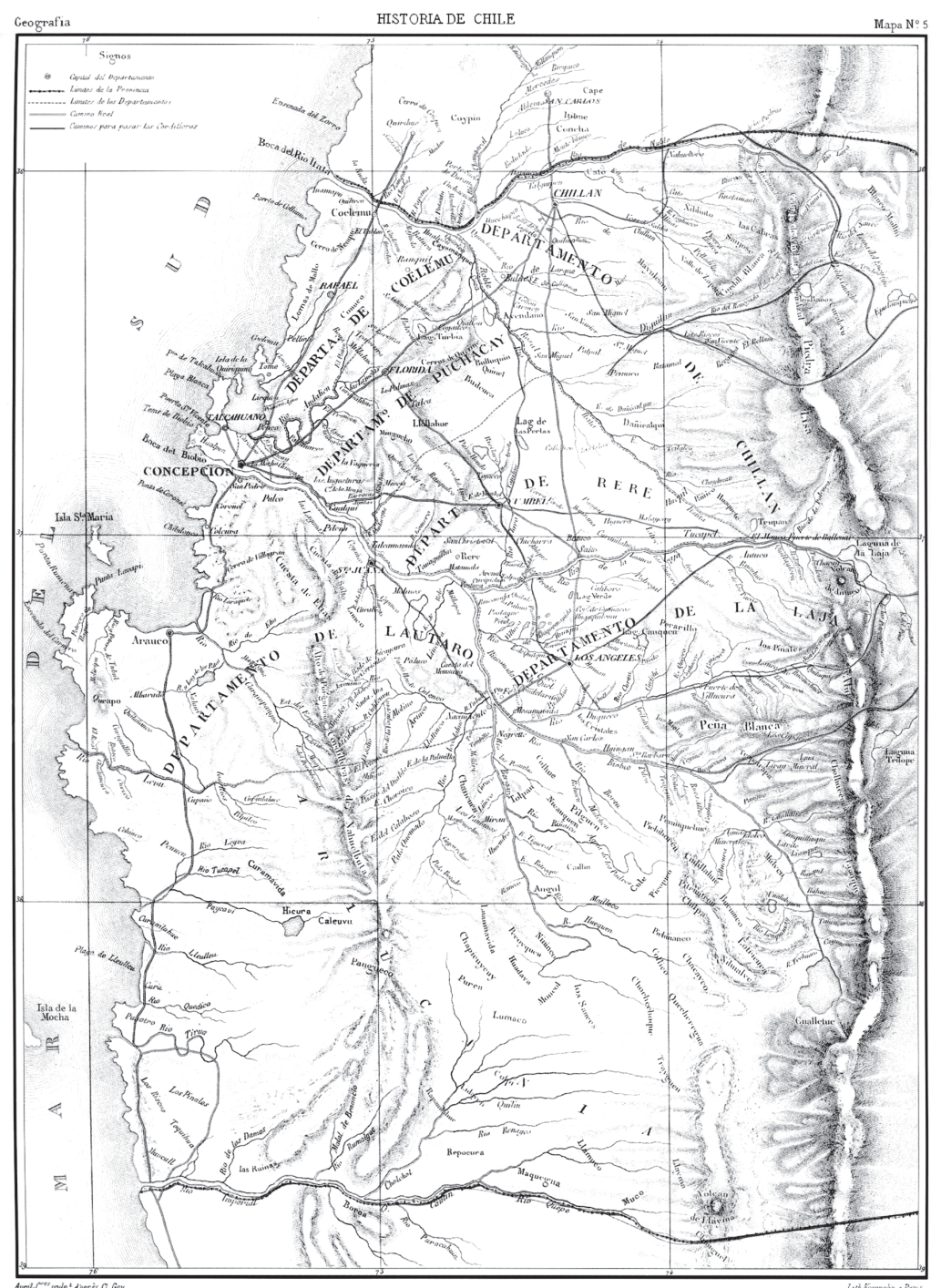

Fuente: Atlas de la Historia Física y Política de Chile (2004). 
de las curvas de nivel, el que mediante trazos de distinta longitud, grosor y proximidad, permite, junto con mostrar las características del relieve, insinuar la pendiente del terreno. En su carta general de Chile, Gay indica además del relieve, la altitud de los puntos culminantes del terreno, calculados por medio del barómetro, altitud expresada en varas españolas. La escala gráfica del mapa utiliza como unidad de medidas de longitud, las leguas española y francesa. La toponimia de este mapa es particularmente escasa. Por su parte, en las cartas particulares de cada provincia la información está adecuada con la escala elegida para su representación. La toponimia litoral identifica bahías, puertos, golfos, penínsulas, etc.; la continental, muestra centros poblados diferenciados según su condición de aldeas, pueblos o ciudades; la hidrografía continental identifica ríos, quebradas, lagos, así como también los accidentes del terreno, representados entre otros, por cordones montañosos, cerros y volcanes. La leyenda de estas cartas no es uniforme, varían de una provincia a otra, aunque ella se reserva preferentemente para indicar los límites provinciales, departamentales, los caminos y los centros poblados.

Por su parte, el sistema de proyección que utiliza Pissis para la confección de su cartografía corresponde a la proyección de Bonne, tanto para la carta de escala 1: 250.000 del año 1873, como para su mapa general de escala 1: 1.000.000 del año 1888. Es la misma que se había adoptado para la construcción de la carta de Francia, la cual tiene la ventaja de no alterar la distancia relativa de los puntos. Para la confección de su cartografía, utiliza exclusivamente las posiciones geográficas tal como resultan de las últimas correcciones y solo PROVINCIAS DE CURICÓ, TALCA, MAULE, LINARES, ÑUBLE, CONCEPCIÓN Y BIOBÍO

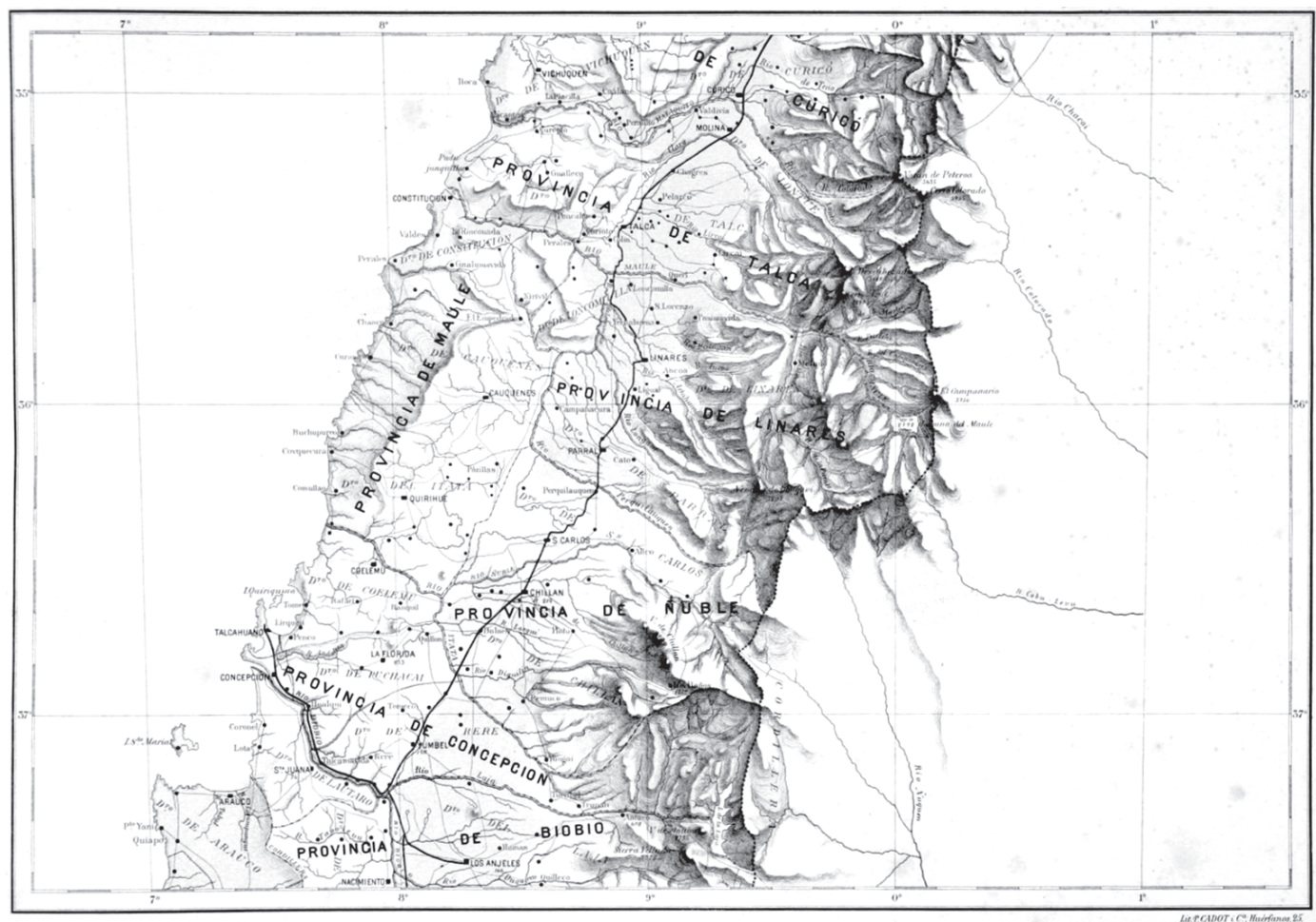

Fuente: Atlas de la Historia Física y Política de Chile (2004). 
hace uso de interpolación para los asuntos de una importancia secundaria. El meridiano base o cero, es el mismo que sirve de punto de partida para contar las longitudes, siendo este el del observatorio del cerro de Sta. Lucía, cuya longitud es de $72^{\circ} 58^{\prime} 32^{\prime \prime}$, al oeste del meridiano de París.

La representación cartográfica 1 : 250.000 de Amado Pissis se inicia un poco más al norte de la ciudad de Copiapó, a los $27^{\circ} 18^{\prime}$ S. y alcanza hasta el seno de Reloncaví, a los 415'․ No obstante, los límites de la triangulación se ubica entre las latitudes $27^{\circ}$ y $37^{\circ} 42^{\prime \prime}$, vale decir que esta solo alcanzó hasta la frontera araucana, por lo que el sector comprendido entre esta última área y el seno de Reloncaví, no tiene como base un levantamiento regular, por lo que en opinión de Edwards, es "un bosquejo informe, harto inferior al de Gay, a pesar de sus pretenciosas dimensiones" (Edwards, 1911: 53).

Para la representación del relieve, Pissis elige al igual que Gay el método de las "normales" pero con sombreado oblicuo, el que otorga un mayor realce al relieve que el vertical, especialmente adecuado para un relieve montañoso como el de Chile.

\section{Conclusiones}

Tanto los levantamientos cartográficos de la República de Chile que ejecutaron primero Claudio Gay y luego Amado Pissis, independiente de los elogios y críticas que fueron objeto por parte de sus coetáneos y analistas posteriores, tienen el mérito de haber dado respuesta a la demanda que las autoridades de gobierno hicieron desde los inicios de la formación de la República, en orden a disponer de una cobertura cartográfica de la mayor parte del territorio, fundada en principios científicos que aseguraran una representación lo más fidedigna del territorio que les correspondía administrar.

En efecto, la cartografía de Claudio Gay, vino a resolver la carencia de una cobertura cartográfica que el país requería con urgencia, la que a pesar de no haber contado su levantamiento con una base fundada en una triangulación geodésica de primer orden, a consecuencia del tiempo que un trabajo de esa naturaleza le habría demandado, debió conformarse con un levantamiento apoyado solo con base astronómica, utilizando para ello instrumentos como el sextante, cronómetro y telescopio, que le permitían cumplir al menos, con los requerimientos básicos de un levantamiento cartográfico científico. Las deficiencias de la cartografía de Gay en cuanto a la precisión del trazado del litoral, localización de lugares, trazado del curso de los ríos, diseño del contorno de los lagos, así como la indefinición del trazado del límite oriental del país, que resultan ser los aspectos más criticados de sus mapas, en nada desmerecen su trabajo en general, en consideración al hecho que el solo levantamiento cartográfico del país, habría sido suficiente trabajo para el tiempo que dispuso; a lo que habría que añadir la falta de colaboradores con suficiente preparación, así como también el instrumental que logró conseguir para desarrollar la tarea encomendada y principalmente, los predecibles errores que se derivan del método empleado para el levantamiento.

No obstante, terminó siendo un gran aporte al conocimiento geográfico del territorio nacional, reflejado en sus productos cartográficos y a la formación de la nación, por la identidad que logra darle al territorio chileno mediante la visión de conjunto que tiene su obra. Hay que ponderar su trabajo a la luz de la escasez de recursos con los que siempre debió luchar, así como también con la falta de personal idóneo del que no siempre pudo disponer para la realización de la tarea encomendada.

Por su parte, la labor cartográfica que el Supremo Gobierno le encomendó a Amado Pissis, tiene para él el mérito de haber estado dispuesto a liderar la ejecución de un levantamiento cartográfico a una escala como la 1:250.000, que presenta importantes desafíos en cuanto a la precisión exigida y el significativo número de datos requeridos para su elaboración. Ello explica en gran medida que el porcentaje más alto de críticas que recibió su trabajo, se concentraron preferentemente en el nivel de precisión que se esperaba de un levanta- 
miento fundado sobre la base de una triangulación geodésica de primer orden, la que no fue posible cumplir cabalmente, de ahí los errores en la localización de ciudades, pueblos, curso de ríos, diseño de la línea de costa, entre otras. Su error fue haber aceptado tal desafío, sin disponer del instrumental de calidad que apoyara su labor de terreno. Valga recordar que recibió instrumental usado que luego él debió complementar; haber prometido sustentar su trabajo en una triangulación geodésica de primer orden que dada la topografía del país difícilmente podía ser aplicada en todo el territorio en igualdad de condiciones por lo que debió recurrir a otros métodos alternativos de menor precisión; haber dispuesto de colaboradores que si bien es cierto estaban profesionalmente mejor preparado que con los que contó Gay, debió soportar constantes cambios de ellos, en virtud de los bajos presupuestos que se le otorgaron para pagar a sus colaboradores. Sin embargo, el asunto que habría incidido más fuertemente en esta deficiencia, según lo señala Alberto Edwards, uno de sus principales críticos, es el hecho que Pissis extravió su libreta de apuntes con los datos recolectados, los que habrían sido reconstituidos en base a sus borradores. No obstante lo anterior, su trabajo contribuyó también al conocimiento geográfico del país, una de cuyas aplicaciones más directas fue facilitar a los legisladores la delimitación política administrativa del país durante el último tercio del siglo XIX.

Las proyecciones cartográficas utilizadas tanto por Gay en su mapa general de Chile como en los especiales para cada provincia, así como la empleada por Pissis, en su carta a escala 1: 250.000 y mapa $1: 1.000 .000$, se adecuan a las características del territorio chileno, caracterizado por su gran extensión en el sentido de la latitud y reducido en el de la longitud. La crítica que habría que hacer a las cartas de las provincias de Gay, es no haber mantenido una escala uniforme de representación, lo que dificulta su comparación al variar ellas entre 1: 800.000 y 1: 1.500.000.

El método que tanto Claudio Gay como Amado Pissis utilizan para la representación del relieve es el denominado de las "norma- les", método de uso común entre los cartógrafos de la época y menos engorroso que el método de las curvas de nivel. Sin embargo, hay una variante entre ellos, mientras Gay utiliza el sombrado de las normales desde la vertical, Pissis lo hace en forma oblicua. Con todo, ambas variantes, caracterizadas por el uso de trazos de distinta longitud, grosor y proximidad, permiten, junto con mostrar el relieve, indicar con bastante aproximación la pendiente del terreno, lo que en el caso del territorio chileno es de gran utilidad para apreciar su variada y rica topografía.

La toponimia tanto del litoral como del interior del continente que acompañan los mapas particulares de las provincias y el dedicado a Chile general de Claudio Gay, es adecuada y ella está en directa relación con la escala utilizada en la representación. Es especialmente propicia para el mapa general de Chile a escala 1: 2.000.000, mientras que va perdiendo eficacia en las cartas particulares de las provincias. Por su parte, la toponimia que se encuentra en la cartografía de Pissis a escala 1:250.000 resulta escasa, como consecuencia de la escala utilizada en la representación, mientras que en el mapa a escala 1: 1.000.000 es adecuada y sobresale por el uso de distintos tamaños de letras, como por ejemplo los empleados para diferenciar en la división política administrativa imperante.

En definitiva, para valorar en su justa medida estos dos levantamientos cartográficos que se llevaron a cabo durante el siglo XIX, hay que ponderar la época y las circunstancias en que ellos se realizaron. Cuando el gobierno le solicita el trabajo a Claudio Gay, el país no dispone de ningún antecedente previo de relevancia, ya sea gráfico o catastral, que pudiese ayudar en su concreción, debe partir prácticamente de cero: desde elaborar el plan de trabajo hasta culminar con la publicación de la obra; preparar el personal de apoyo para su trabajo en terreno y sus colaboradores de gabinete. Claudio Gay era un naturalista pero no un geógrafo o agrimensor. Sin embargo, adquirió la preparación necesaria para realizar un levantamiento cartográfico de un territorio tan vasto y con una topografía tan particular como Chile, con resultados que lograron el 
objetivo inicialmente propuesto, como era el poder dejar una herramienta que dio las primeras luces de la dimensión y alcance del territorio chileno, en el momento que la nación requería de ella para una administración eficiente.

Algo muy similar ocurre con el trabajo desarrollado por Amado Pissis y aunque cuando él inicia sus actividades en 1848, todavía no se publicaban los resultados de su antecesor ni menos su cartografía. Pissis al igual que Gay, también debió comenzar su trabajo con muy pocos antecedentes y probablemente las expectativas de las autoridades de gobierno fueron mayores en su caso, en atención a que él tenía una formación específica en lo geológico y geográfico. Además, ofreció desarrollar un trabajo de mayor precisión en lo cartográfico junto con una prospección de los recursos minerales, asuntos de la mayor importancia para una nación que está en proceso de fortalecer su economía. Para algunos de sus coetáneos, los resultados logrados por Pissis fueron decepcionantes al detectar errores de ubicación, localización y diseño de cordones montañosos, ríos y localidades.

Con todo, los resultados cartográficos logrados tanto por Gay como por Pissis son positivos, dado que se cumple uno de los propósitos centrales que las autoridades de gobierno se habían trazado, como era disponer de una cobertura cartográfica de la mayor parte del país, sin embargo, un segundo propósito relacionado con la precisión de los levantamientos, no logró satisfacer plenamente las expectativas previstas.

\section{Referencias bibliográficas}

EDWARDS, A. Un nuevo mapa de Chile. Revista Chilena de Historia y Geografía, 1911, № 1, p. 49-70.

ERRÁZURIZ, A. M. Los primeros avances geográficos para el reconocimiento del territorio nacional (1810-1860). Boletín Informativo Instituto Geográfico Militar, 1981, II trimestre, p. 12-16.

FELIÚ, G. Perfil de un sabio: Claudio Gay a través de su correspondencia. En: STUARDO, C. Vida de Claudio Gay. Santia- go: Fondo Histórico y Bibliográfico José Toribio Medina - Nascimento, 1975, Tomo II.

GANGAS, M. La evolución de la Geografía chilena durante el siglo XX. Contextos, tendencias, autores. 2 Vols. Tesis doctoral inédita. Barcelona: Universidad de Barcelona, Facultad de Geografía e Historia, 1985a.

GANGAS, M. Los temas de investigación práctica en la geografía chilena (18301980). Revista de Geografía Norte Grande, 1985b, № 12, p. 49-63.

GAY, C. Historia física y política de Chile, París, 1844-1865. Santiago: Muestra Museo de Historia Natural de Santiago, 2007.

GONZÁLEZ, J. I. La expedición Malaspina y la cartografía sobre Chile. Revista de Geografía Norte Grande, 2004, № 31, p. 7-29.

GREVE, E. Don Amado Pissis y sus trabajos geográficos en Chile. Santiago: Imprenta Universitaria, 1946.

GREVE, E. Breve resumen de la historia de la cartografía nacional. Revista Geográfica de Chile Terra Australis, 1950, № 4, Año III, p. 9-21.

KISH, G. La carte image des civilisation. París: Editorial Senil, 1980.

MARTíN, M. Cartografía Marítima Hispana. La imagen de América. Madrid: Lunwerg, 1993.

MEDINA, J. T. Ensayo acerca de una mapoteca chilena. Santiago: Editorial Ercilla, 1889.

NUÑEZ DE LAS CUEVAS, R. Cartografía Española en el siglo XVIII. En: OBSERVATORIO ASTRONÓMICO NACIONAL. Astronomía y Cartografía de los siglos XVIII y XIX. Madrid: Observatorio Astronómico Nacional, Comisión Quinto Centenario, 1987, p. 33-52.

PISSIS, A. Descripción topográfica y geológica de la provincia de Colchagua. Anales de la Universidad de Chile, 1860, p. 559-715. 
PISSIS, A. Plano topográfico y geológico de la República de Chile, 13 hojas, levantado por orden del Gobierno. Escala 1: 250.000. París: Grabado por N. Desmadryl, Impreso por Ch. Chardon, 1972-1973.

SAGREDO, R. El atlas de Claudio Gay y la obsesión por representar Chile. En: CENTRO DE INVESTIGACIONES BARROS ARANA. Atlas de la historia física y política de Chile. Santiago: Lom Ediciones, Centro de Investigaciones Barros Arana, DIBAN, 2004, Tomo I.
SAGREDO, R. y GONZÁLEZ J. I. La expedición Malaspina en la frontera austral del imperio español. Santiago: Editorial Universitaria, Centro de Investigaciones Barros Arana, 2004.

STUARDO, C. Vida de Claudio Gay. Escritos y Documentos. Santiago: Fondo Histórico y Bibliográfico José Toribio Medina Nascimiento, 1973. 